\title{
Service-learning: New Dimensions to Usual Practice
}

\author{
Florence McCarthy* \\ Centre for Educational Research, Western Sydney University, Locked Bag 1797, \\ Penrith NSW, 2751, Australia
}

\begin{abstract}
Educating the heart" has long been a theme in service-learning indicating the importance of developing awareness, understanding and respect for people unlike oneself. Particularly at the tertiary level, however, changing conditions and pressures on universities and colleges to produce "employment ready" students, manage with reduced funding and adjust to changing academic priorities can pose real challenges to service-learning programs. This article explores situations which may deflect the ability of service-learning programs to fully develop aspects of educating the heart. Additionally, the article suggests alternatives that can promote reinvigorated service-learning programs featuring intercultural understanding, strong multi-cultural ties and viable social relationships among students and with social organizations, community groups, and local people.
\end{abstract}

Key words: Changing practice, educating the heart, employmentreadiness, intercultural, service-learning

\section{Introduction}

The theme of "educating the heart" has been a centre-piece of service-learning programs in Asia for many years [1]. Although in today's world it is just as critical as ever, the environments in which service-learning operates make it increasingly difficult to realize. Now more than ever it is critical to review approaches to service-learning and to explore challenges and opportunities to improve the general methods employed in educating the heart. The purpose of this paper is to explore situational and institutional arrangements which may deflect the ability of service-learning programs to fully develop aspects of educating the heart.

Educating the heart refers to creating empathy, understanding and openness toward people who are unlike ourselves. It means being aware of the conditions that create disparities among people and being willing to do something to ameliorate these inequalities. It means developing a collective consciousness to work with others in achieving a collective good. Educating the heart often requires as much unlearning of unconscious bias against others as it does learning to be open to difference.

\footnotetext{
* Corresponding author: ide@,iinet.net.au
} 
The globalized world in its many forms creates challenges in all arenas of social life. The pursuit of neo-capitalist policies by national governments, for example, have fostered a turn away from government serving the people to government serving the interests of the rich. People live with cut-backs to basic education, health care, welfare, and family assistance programs. Diminishing returns for hard work characterizes the lives of many everyday people while trickle-up policies deliver ever-increasing wealth to the very rich. In the economic realm, processes of robotization, technological advances, and outsourcing contribute to the growth of economies without commensurate job creation [2]. The thousands of full time jobs that were lost during the Great Financial Crisis have never been restored, and employment in newly created jobs often features low wage, part-time, contract or benefit-fee work [2]. This means there has been unprecedented growth in the numbers of people, particularly young people, who are unemployed or are underemployed in low-paying work [3]. Moreover, people everywhere are aware of the dangers of climatechange, the devastation caused by conflict, and the horrific effects on people driven from their homes and forced to seek refuge in other parts of the world.

These large-scale issues create problems for the individual-problems of connection, of belonging, of feeling worthwhile, and of creating satisfying lives for themselves. These forms of alienation, of people feeling detached from others, from their communities, and from their governments have contributed to the rise of populism, new nationalist movements, and religious fundamentalisms.

Now more than ever the need is for efforts to be made to bring people together, to counteract the moves to fragmentation with those of cohesion and collective purpose. Education is uniquely situated to play a pivotal role in this, as it is a central part of lifewhether we have it or not, education is recognized as a universal good - an essential element for improving the life-chances of people. For those who can go to school, education shapes the thinking, provides the knowledge, and establishes the behaviours required of students to function in the larger world. So much promise is possible in these institutions. Often so much is lost through outdated pedagogies, lack of funding and resources, the adequate training of teachers, and by the adherence to traditional modes of belief in what education is and what it can deliver.

Institutions face their own challenges, however. At the university level, for example, issues include making students "job ready," cutting programs that don't contribute to employment options, providing basic curricular content that may be outdated because institutions often lack the funds to update technologies, provide the staff training, and/or fund the libraries and computer labs. Many universities may experience a continuous lack of resources for faculty salaries, buildings, and facilities.

Service-learning is one small alternative in changing the standard provision of education as it links important but disparate elements of schools/universities with local agencies, communities or local government [4]. This is a natural possibility for creating immensely engaging and beneficial connections among people who most often have little in common with each other.

Central to this dynamic are administrators and faculty and perhaps trustees at the university level; leaders and local people within communities; directors and staff along with beneficiaries in local agencies, and of course, students who are the reason all this happens.

Probably one of the most critical issues facing service-learning programs is success. Because success means service learning initiatives have widespread popularity with students; all the pieces of good service-learning programs have been lined up; the students enrol or join the program, they learn a lot from the experience; faculty are not excessively overworked and administrators continue to support it. So, the established program continues. Programs, however, can become routinized, become part of the curriculum and 
in the process perhaps lose the option of remaining ground-breaking, creative, and unique in what service-learning offers.

Now be assured this is not an attempt to diminish the tremendous efforts that have gone into efforts to make institutional service learning a success. Instead what is being offered is a challenge by asking: how well has the education of the heart been going? What can be done to add new dimensions to the usual practice of service-learning?

Why is this necessary? Because with any success comes new challenges and problems. They are likely to be unexpected, not anticipated when service-learning programs were first developed. The social, political and economic contexts in which programs operate also change and provide new issues which must be confronted. For example, the pressure to create "job ready" graduates can pose threats to service learning programs which tend to focus on reciprocal learning and reflective experiences [5].

Given the condition of the world now, the main asset of people in the future will be each other. How they relate, support, encourage and engage with others will be key in protecting themselves from destructive forces.

Everyday people only have their considerable numbers to defend and oppose destructive forces. Therefore, how people are encouraged to see shared interests and place value in mutually reinforcing relationships becomes a central issue to be addressed. It is also important to enquire, how does this affect service-learning?

Service learning embodies both dimensions of good education-creating communities among and across those who participate in it, and providing challenging pedagogy based on structured experience and guided reflection to transform students' understanding of their social world and the issues inherent in it.

The pages to follow will explore how participants in service learning have the opportunity to create communities of support for the education of the heart.

\section{University-community/agency partnerships}

Silliman University in the Philippines has been quite effective in building trust and reciprocal learning relationships between university faculty and local barangay communities. The program described here was current a number of years ago, but it's organization exemplifies meaningful university-local community relationships. In beginning the program, University faculty visited local barangays to discuss with local leaders the ways that service-learning faculty and students could assist the local community in improving services, technology, health, agriculture or whatever else was identified as problematic by local people [6].

Local leaders worked with Silliman faculty in planning what activities could be undertaken, how they might be organized and implemented, how local people would assist in these activities, and how university students would be involved.

Through this process, agreement was reached about the contributions of both partners in the service-learning project, including such activities as students doing a general census of the barangay, an assessment of villagers requiring special services for the aged or physically impaired, health issues for women and children, assisting in local schools in special areas of need, and so on. Each of these topics was the basis for faculty from relevant departments to prepare their students for involvement in the barangay by linking village needs to relevant course work in the students' degree programs [7].

Because of the time it takes to establish good workable ties among universities and local villages, it is wise to assume a long-term association with local communities, rather than short term involvement. Over time, the actual activities within an area such as health may change, but the commitment remains of both the university to have students available for projects and the local people's willingness to assist and support these activities. 
The advantage of a long-term commitment, for example $5 \mathrm{yr}$, is that it ensures time for projects to unfold, and with implementation to establish the means for the training of village/community people to make real differences in the lives of local people. For example, in the Silliman program, service learning students made a difference by providing health care for pregnant or new mothers, vaccinating children, caring for the elderly and training family members in their care. Successive groups of students can usefully mentor local children in math and science or English; engineering students can help develop flood control or better roads.

People come to know each other; villagers can see the benefits of their planning and their input to university-based service-learning projects. With long term projects, it is possible for local people to acquire skills that they can employ in continuing what has begun in various projects-caring for machinery, repairing roads, growing vegetables, supporting schools, treating the elderly in new ways. In exchange, the university has generated strong support among local people. They know what educated people and willing students can bring to a village. They are likely to remain staunch defenders of education.

Filipino university students have perhaps what will be a once-in-a-lifetime rural experience before securing employment at the end of their degree programs in urban centres. The results of such experience will hopefully remain with them; making them sympathetic to rural issues, and to the difficulties rural people face.

To summarize, new dimensions of university-community partnerships expand the focus of the relationships involved. From the university seeking community support in training and preparing university students in practical aspects of their fields of study, the commitment shifts the focus to assisting village people in creating and finding solutions to the problems they face. From a temporary and indeterminate relationship based on the commitment of a few faculty, the university can undertake to establish a multidisciplinary unit which operates as the contact group for the university with local communities/agencies. Individual faculty may circulate in and out of the unit, but the unit continues over time. (Another alternative would be to have a service-learning department complete with projects specifically designed by departmental faculty in conjunction with local agencies and communities. Coordination among faculties could also occur, and the overall support of the university administration remains.) Finally, the university becomes a long-time player in assisting local communities to improve their conditions. This includes establishing forms of resources (including participatory research) or other forms of support for local people after the university finishes its contract with the communities. In return, community support for the university grows, and the interest in education is reaffirmed.

\section{University-faculty relationships}

Faculty commitment to service-learning remains the critical variable in ongoing servicelearning programs. Regardless of how the delivery of service-learning is organized, whether departmentally-based or through an established office, campus faculty must remain convinced of the value of service-learning and share an appreciation of the positive learning outcomes it can create. It is not necessary that every faculty member participate in servicelearning, but it is important that they support the efforts of others to engage students in different forms of learning. Equally important is the continued support of the university/college administration to these programs.

The difficulties faculty members encounter in sustaining their interest in servicelearning are well known. Issues relate to the time service-learning takes for faculty to prepare for and actually teach such classes. Other issues faculty face within the university context include teaching loads, research and publishing obligations as well as committee work and meetings. There are problems arising from funding or resource constraints, and 
the need for continuing support from other department members, other faculty and the administration. Ameliorating these difficulties depends on the success of the program, especially if the elements of its success include contributing to the reputation of the institution as being unique because of its service-learning programs.

Possible new challenges for faculty are likely to arise as the pressure builds to ensure that new graduates are "employment ready". In many countries, the response to this demand is to add a "practical dimension" to basic classroom learning, assuming that an exposure to the real world will help qualify students for employment in globalized settings [8]. So out-of-classroom experience is included in the student curriculum, or is included as short multicultural experiences in the form of modules within various courses. Internships, work experience, and summer placements are elements being added to ongoing courses. In many fields, an emphasis is placed on students learning 'soft skills' such as communication skills, ways of behaving in intercultural situations and general cultural sensitivity is now regarded as basic to business, management and communication degrees [8]. The issue is not whether or not these are valuable student experiences, or whether they increase the employability of students. The issue is how to ensure service-learning encompasses both the skills relevant to employment and a more nuanced understanding of social issues, the difficulties faced by many people, and a sympathy for others unlike themselves. What is being emphasized is the distinction between simply preparing students for the workforce and actually creating in them empathy and an appreciation of difference. These are elements of educating the heart. Institutions and faculty that wish to promote servicelearning as unique must focus on what makes it unique in each location and be willing to defend the special features of their programs.

Exploring and celebrating uniqueness calls for i) greater collaboration and cooperation among service-learning faculty on campuses to create synergies of support, learning and outreach, ii) continued and long-term reciprocal learning relationships among servicelearning partners, including ongoing efforts to secure the support of the Administration and iii) the inclusion of both regular summative and evaluative research that involve all participants and that analyses both strengths and problems within service-learning activities. In this way, problems can be identified and quickly solved, and the programs remain dynamic and satisfying to all concerned.

An important fourth element would be the pursuit of new forms of faculty research that documents the offshoots of service learning and that informs research interests generic to other disciplines. For example, service learning programs can drive research related to other disciplines such as mentoring or intercultural communications, even in fields as diverse as engineering or nursing. Creating research profiles among service-learning faculty is another way of securing ongoing administrative support for what they do.

\section{Faculty-student relationships and new forms of learning}

With service-learning classes, faculty have the opportunity to create new forms of instruction, and new patterns of interaction with students. It is the chance to break the increasingly corporate style of teacher-student relations, including distance learning that minimizes face-to-face interaction. Faculty can make a number of small changes in how they relate to students and how they teach their classes that can transform students' engagement with learning, establish communities of learning and practice, and modify their own approach to teaching.

Among the changes that can be made are: First, clarifying the theories and concepts that are most important for students to know and learn [9]. This requires building a curriculum around making these the central focus of the course. These main elements of the course also need to be integrated with the service activities that students will undertake, and 
included in structured reflections with students, both written and in debriefing sessions when they return to class from the field.

Doing this requires purposeful planning and flexibility. Encouraging students to bring issues, dilemmas, problems, situations and successes into open classroom discussion means planned lessons will be disrupted by student's situations or questions. Somehow the linking of academic knowledge must be incorporated into teachable moments as they arise: unscheduled, random, crucially important but unpredictable. Challenged as well may be traditional teacher-student relationships where knowledge and instruction is the purview of teachers and learning and repeating lessons is the responsibility of students. More reciprocal learning and exchange can be generated from dynamic service learning classes, relaxing standard modes of classroom interaction. Encouraging regular group discussions among students about their experiences is another way of creating relationships among them that is important in forming communities of practice [10].

Second, the preparation of students for their placements should include knowledge and skills both. In enquiring with SLAN colleagues about their preparation courses, they indicate that many students feel they don't have anything to offer other people, and often lack basic skills that would facilitate their interaction and relationships with strangers [11]. Consequently, practice-based preparation is increasingly important to our service-learning classes. Students can be taught basic communication skills and given protocols to guide their interaction with mentees. This provides them a way of asking questions without being judgmental, and conversing with others without providing opinions or suggestions for what should be done. Students can be encouraged to engage in games or exercises that rely on listening, as this as a critical skill for successful interaction with others. Role playing is another way of giving students the experience of talking with people they don't know and who are very different from themselves.

Third, reflection, in many forms, remains a critical variable in transforming student experience into learning and knowledge. Structured forms of reflection-through classroom discussions, through interaction with other students in debriefing sessions, and through written assignments-all can operate to encourage students to make sense and create meaning out of the experiences they have. The prior experiences and backgrounds of students also influence their perceptions of the world, so students bring that history with them. For example, one of the mentors in the Equity Buddies program, which will be discussed a little later, admitted, 'I'm ashamed to say I've never spoken to a Muslim person until I took this class."

\section{Students in a moving dialogue with teachers, agencies, local people and each other}

While students may recognize the need for acquiring tertiary degrees in the pursuit of evermore elusive employment, many of them may find the campus-based educational process uninspiring and dull. Learning environments on campuses may sometimes fail to offer a curriculum that matches student interests, or may fail to lead to employment. As a result, many students go through the motions of getting degrees, and may be present but not engaged with the process.

Service learning offers an opportunity for students to apply knowledge in real situations and generate forms of engagement with learning from non-academic sources: from agency staff, from local people, and from other students. The challenge of meeting and interacting with people who are different, of developing new skills such as listening and negotiating ways of completing tasks in strange environments are all ways that new skills are learned and implicit stereotypes, assumptions, and perspectives on the world can be challenged and 
changed. The more students are involved in their learning, the more meaningful it is likely to be. Service-learning has the potential to create these learning situations.

\section{Intercultural service-learning for students at home and abroad}

In terms of the globalization, acquiring intercultural understanding becomes critically important for young people. Service-learning brings together experiential practice with guided academic readings, theories and concepts, enhanced by structured reflections and discussions that promotes such understanding. It is the combination of these factors and how they are utilized in the teaching-learning environment that makes intercultural learning successful.

Many of the service learning programs in Asia include multicultural dimensions to them. These are important efforts to create situations where students from different cultures work together often in small groups or teams in their service activities. As Colvin and Volet [12] point out, local students rarely take advantage of opportunities for interaction with culturally-different students. The programs of the Service Learning Asia Network (SLAN)have promoted multicultural service learning for many years, and continue to do so. From these programs, it has been learned that intercultural awareness and understanding can be created by bringing students from different cultures together in small teams to engage in sustained service in culturally unfamiliar locations [13-16].

There is much that can be done on local campuses in bringing different groups together. As service learning activities are expanded, new forms of service learning can be developed and introduced on local campuses. As a way of showing how this can be done, an example is given below of a multi-cultural, cross-level mentoring program that is being implemented at a university in Australia.

\section{Equity buddies: A multicultural cross-level mentoring program}

The example is the Equity Buddies program currently underway at the Western Sydney University in Australia. This is a cross-level academic mentoring program which pairs students from different cultural/religious/ethnic backgrounds in weekly mentoring sessions and debriefing meetings. Western Sydney University enrols students of whom $67 \%$ speak languages other than English at home. Arabic along with Chinese and Vietnamese are popular languages students speak, and about two-thirds of the student body are from families of low socio-economic status, and many are the first in their families to attend university. The aim of encouraging second or third year students to act as mentors to first year university students, the mentees, is to create connections so that mentees learn what they need to know to succeed at university. As has been well documented, first year students often lack basic knowledge about the services provided by the university, don't know how to manage their time, or don't know how to use the library or computers, and often find even the course outlines difficult to understand [17]. Moreover, the important "hidden knowledge" that senior students have mastered is often critical in helping new students deal with university life.

Equity Buddies creates $10 \mathrm{wk}$ combinations of lectures and tutorials and weekly meetings of mentors/mentees. Providing the supports and skills that help mentors assist their mentees is one way the mentoring experience works for both parties; mentors feel confident they have information to offer, and mentees find the relationship with their mentor to be satisfying in academic and socially important ways. Over time, what begins as 
pure required interaction becomes comfortable relationships or even friendships among the students [18].

Mentors and mentees also meet separately in debriefing groups where six or seven other mentors or mentees discuss their experiences, share problems, get help and receive guidance from a student facilitator. This approach creates communities of learning among students [16]. The research that has been done to explore the experience of mentors in particular, has been particularly relevant to issues of Intercultural communication. It has shown how sustained contact among students from different cultural/refugee/ethnic backgrounds can create relationships that breakdown stereotypes held about students who are different. Sustained interaction also can create new patterns of understanding and appreciation of students from different cultures and religions, and expand the confidence of students to interact with and be open to other students who come from cultures different from their own [18]. The results of this research indicate that sustained, supported interaction among students from different backgrounds can create meaningful reciprocal forms of learning and cultural openness.

Debriefing groups are the most novel innovation in this program. Students often learn more from other students than from "adults," and are likely to trust students more than staff or faculty. By bringing groups of student mentors together to discuss their experiences with their mentees, mentors learn from each other about what works or doesn't; how to tackle problems, share possible solutions to difficulties; maintain boundaries, and help one another's mentee. To overcome the reluctance of students to interact with others who are culturally different, mentor-mentee pairs and debriefing groups are deliberately composed of students from different cultures. Over time, through positive interaction, suspicion is replaced by connection, liking support, and friendship [18]. The learning communities these groups form become a powerful force for transformative learning and understanding about students from other cultures. The effect of this interaction can carry over onto the campus too as it helps break down the separation of ethnicities and religions into different, noninteracting groups.

\section{New dimensions to usual practice of educating the heart}

To summarize, the attempt has been made to challenge the thinking about service learning engagement by suggesting that new dimensions of educating the heart should lead to expanded efforts in all areas of education to make it more inclusive, cooperative and supportive.

With rising populist movements in many countries, for example, educational systems may increasingly become vulnerable and threatened as populist leaders perceive education to be a threat to their control of others. Neo-conservative economics is also a conservative movement and under its influence, universities and entire educational systems may experience severe cuts in resources, reductions in staff and institutional support and even closure.

One way universities can offset these possible challenges is by changing their approach to community engagement. Instead of using communities to achieve university interests, universities instead can create strong, inclusive and reciprocally beneficial partnerships with local communities and agencies in order focus on working collectively to solve local problems. In return, local people can develop different ideas about educated people and about what educational institutions can do in working with them in making their lives better. As an outcome, local support for educational institutions can be created through the development of these communities of support. In these endeavours service-learning programs can be extremely important in bringing participants together in new forms of association and solidarity. 
Increasingly faculty and staff are likely to come under pressure to respond to corporate and government demands to create employment-ready students. To respond to these demands, faculty will need to cooperate across disciplinary-boundaries to maximize the education of the heart by working together to create ongoing ties with agencies and communities to promote useful service, while also encouraging reflective processes that expands the outlook of students to include different people, attitudes and values in their lives. Sharing difficulties, and creating mutual forms of support in making strong service learning classes is one way of sharing the load that service learning often entails. Additionally, processes linking classroom academic work to students' experiences of service, especially student lead discussion groups, is one way to promote greater appreciation and understanding of local people on the one hand, and create supportive communities of learners on the other. Inherent in these activities are classrooms where learning is reciprocal, focused, purposeful and inclusive. If education of the heart is the focus of service-learning then it is also the center piece of academic teaching and learning.

For students caught up in inclusive, dynamic and meaningful experiential educational classrooms, learning can be transformed. Connecting real-life situations with the experience of others, applying concepts and readings to help understand what's going on, and ensuring that students feel their efforts make a difference, all contribute to students forming a different opinion about education. Not only have they experienced making a difference, students have also developed empathy, and understanding and made connections with others unlike themselves. In the process, they have enhanced the education of their hearts.

In summary, the purpose of this article has been to illustrate the ways all participants in service-learning undertakings can fashion new responses to shaping their contributions to the education of the hearts of their students. The context and demands on service-learning programs throughout the world constantly require flexibility and adaptability in creating learning environments that link classroom reflection with community engagement.

\section{References}

1. F.E. McCarthy. Educating the heart: service learning and Asian institutions of higher education. Report prepared for the United Board for Christian Higher Education in Asia and the International Partnership for Service Learning. New York (2001). [Internal document].

2. J.W. Yun. Korea Observer 45, 4, Winter 2014: 545-575 (2014). https://www.kci.go.kr/kciportal/ci/sereArticleSearch/ciSereArtiOrteServHistIFrame.kci? sereArticleSearchBean.artiId=ART001966625\&sereArticleSearchBean.orteFileId=KCI FI001966625.

3. R. Torres. International Labor Review, 152, 2:167-173 (2013). https://onlinelibrary.wiley.com/doi/pdf/10.1111/j.1564-913X.2013.00175.x

4. F. E. McCarthy. New Horizons in Education, 57, 3:8-19 (2009). https://www.researchgate.net/publication/266467332

5. Andrews, H. Higson. Journal Higher Education in Europe, 33, 4:411-422 (2008). https://www.tandfonline.com/doi/abs/10.1080/03797720802522627

6. E.G. Oracion. Intercultural service-learning as crossing borders: Experiences in the Philippines and India. Paper presented at the 2nd Asia-Pacific Regional Conference on Service-Learning: Crossing borders, Making Connections: Service-Learning in Diverse Communities, Hong Kong and Guangzhou, China (Lingnan University, Hongkong, 2009). http://commons.ln.edu.hk/osl_conference/2nd/breakout_6/3/ 
7. E.I. Ligutom. Service learning in Silliman University. Lessons from service-learning in Asia: results of collaborative research in higher education. Tokyo: International Christian University: Service Learning Center (2009). pp. 159-185. ISSN 1881-6282

8. G. Abermann, M. Tabuenca-Cuevas. Education for workplace diversity: what universities and enterprises can do to facilitate intercultural learning in work placements abroad. Champaign, Illinois: Common Ground Publishing (2017). pp. 3256.

https://books.google.co.id/books?id=blGMDAEACAAJ\&dq=Education+for+Workplac e+Diversity:+What+Universities + and + Enterprises + Can + Do + to + Facilitate + Intercultural + Learning + in + Work + Placements + Abroad\&hl $=$ en \&sa $=$ X\&ved $=0$ ahUKEwiAscii6LTdA hXJRo8KHdkHBN4Q6AEIKTAA

9. K. Heffernan. Journal of Contemporary Water Research \& Education, 5-9 (2001). https://opensiuc.lib.siu.edu/cgi/viewcontent.cgi?referer=https://scholar.google.com.au/\& httpsredir $=1 \&$ article $=1160 \&$ context $=$ jcwre

10. M.K. Smith. Jean Lave, Etienne Wenger and communities of practice [Online] from http://www.infed.org/biblio/communities_of practice.htm (2009). [Accessed on 23 March 2017]

11. M. Murakami (2015). Notes on service-learning program by ICU - Nanking reconciliation program. Personal communication. Tokyo, Japan.

12. C. Colvin, S. Volet. International Journal of Intercultural Relations, 42, 77-92 (2014). https://www.sciencedirect.com/science/article/abs/pii/S0147176714000601

13. Service Learning Center. (2009). Service-learning studies, No. 4, lessons from servicelearning in Asia: results of collaborative research in higher education. Tokyo: International Christian University. ISSN 1881-6282

14. Y. Sato, F. McCarthy, M. Murakami, T. Nishio, K. Yamamoto. An appreciation of cross-cultural differences through international service-learning at International Christian University. In: Service-leaning in asia, curricular models and practices, J. Xing, C.H.K. Ma (Eds). Hong Kong: Hong Kong University Press (2010). pp. 31-46. https://www.jstor.org/stable/j.ctt1xwf3j. ISBN 978-988-8028-46-7.

15. J. Xing, C.H.K. Ma, (Eds). Service-leaning in Asia, Curricular Models and Practices. Hong Kong: Hong Kong University Press (2010). https://www.jstor.org/stable/j.ctt1xwf3j

16. F.E. McCarthy, M.H. Vickers, K. Zammit. Facilitators as pedagogical leaders: The acquisition of requisite forms of capital in university settings. In: Contemporary issues of equity in education, S. Gannon and W. Sawyer (Eds). U.K.: Cambridge Scholars Publishing (2014). Pp. 88-99. https://www.cambridgescholars.com/contemporaryissues-of-equity-in-education

17. R. James, K. Krause, C. Jennings. The first-year experience in Australian universities. findings from 1994-2009. Melbourne: University of Melbourne: Centre for the Study of Higher Education (2010). https://trove.nla.gov.au/work/37378647

18. M. Vickers, F. McCarthy, K. Zammit. International Journal of Intercultural Relations, 60:198-209 (2017).

https://www.sciencedirect.com/science/article/abs/pii/S0147176717301980 